\title{
Relationship of proteinases and proteinase inhibitors with microbial presence in chronic lung disease of prematurity
}

\author{
Philip L Davies, ${ }^{1}$ O Brad Spiller, ${ }^{1}$ Michael L Beeton, ${ }^{1}$ Nicola C Maxwell, ${ }^{1}$ \\ Eileen Remold-O'Donnell, ${ }^{2}$ Sailesh Kotecha ${ }^{1}$
}

- Supplementary data are published online only at http:// journal.bmj.com/content/vol65/ issue3

${ }^{1}$ Department of Child Health, Cardiff University, School of Medicine, Cardiff, UK

${ }^{2}$ Immune Disease Institute and Program in Cellular and Molecular Medicine, Children's Hospital Boston and Department of Pediatrics, Harvard Medical School, Boston, Massachusetts, USA

\section{Correspondence to}

Dr Brad Spiller, Department of Child Health, Cardiff University, 5th Floor, University Hospital, Heath Park, Cardiff CF14 4XN UK; SpillerB@cardiff.ac.uk

Received 4 March 2009 Accepted 1 December 2009

\section{UNLCKI:}

This paper is freely available online under the BMJ Journals unlocked scheme, see http:// thorax.bmi.com/site/about/ unlocked.xhtml

\section{ABSTRACT}

Background A proteolytic imbalance has been implicated in the development of "classical" chronic lung disease of prematurity (CLD). However, in "new" CLD this pattern has changed. This study examines the longitudinal relationship between neutrophil proteinases and their inhibitors in ventilated preterm infants and their relationship to microbial colonisation.

Methods Serial bronchoalveolar lavage fluid was obtained from ventilated newborn preterm infants. Neutrophil elastase (NE) activity, cell counts, metalloproteinase (MMP)-9, MMP-9/TIMP-1 complex, SerpinB1 concentration and percentage of SerpinB1 and $\alpha_{1}$-antitrypsin (AAT) in complex with elastase were measured. The presence of microbial genes was examined using PCR for $16 \mathrm{~S}$ rRNA genes.

Results Statistically more infants who developed CLD had NE activity in at least one sample (10/20) compared with infants with resolved respiratory distress syndrome (RDS) (2/17). However, NE activity was present in a minority of samples, occurring as episodic peaks. Peak levels of MMP-9, MMP-9/TIMP-1 complex, percentage of AAT and SerpinB1 in complex and cell counts were all statistically greater in infants developing CLD than in infants with resolved RDS. Peak values frequently occurred as episodic spikes and strong temporal relationships were noted between all markers. The peak values for all variables were significantly correlated to each other. The presence of bacterial 16S rRNA genes was associated with the development of CLD and with elevated elastase and MMP-9.

Conclusion NE activity and MMP-9 appear to be important in the development of "new" CLD with both proteinase and inhibitor concentrations increasing episodically, possibly in response to postnatal infection.

\section{INTRODUCTION}

Chronic lung disease of prematurity (CLD, also called bronchopulmonary dysplasia, BPD) causes ongoing respiratory morbidity and mortality in preterm infants ${ }^{1} 2$ and is associated with large oversimplified alveoli suggesting aberrant lung development (sometimes called "new" CLD/BPD). Inflammation is a hallmark in the development of CLD, with neutrophils and macrophages releasing reactive oxygen species and proteolytic enzymes including the serine proteinase neutrophil elastase $(\mathrm{NE})^{4}$ and matrix metalloproteinases including MMP-9. ${ }^{6}$ Normally, any free proteinase is effectively neutralised by proteinase inhibitors. Tissue inhibitors of matrix metalloproteinases (TIMPs) are regulators of MMPs, which for MMP-9 in the lung is primarily TIMP-1. ${ }^{5-7}$ For NE, the best characterised is $\boldsymbol{\alpha}_{1}$-antitrypsin (AAT) with which it forms an irreversible covalent 1:1 complex; other proteinase inhibitors include secretory leukoproteinase inhibitor (SLPI), elafin, $\alpha_{2}$-macroglobulin and SerpinB1 (originally called monocyte neutrophil elastase inhibitor) which rapidly binds covalently with NE. SerpinB1 has been studied in rat and mouse models and in newborn baboons but not in human preterm infants.

Early studies reported proteolytic imbalance in preterm infants developing classical CLD. ${ }^{8-10}$ "New" CLD shows a different pattern with elastase activity being less frequently reported. ${ }^{11-15} \mathrm{An}$ imbalance between MMP-9 and TIMP-1 has also been described, but the importance of MMP-9 in the development of CLD remains unclear. ${ }^{5-7} 16-18$

The aims of this study were (1) to serially measure NE, AAT, SerpinB1, MMP-9 and MMP-9/TIMP-1 complex in bronchoalveolar lavage (BAL) fluid of preterm infants at risk of developing CLD; (2) to examine the relationships between these variables and their relationship with CLD development; and (3) to correlate enzyme dysregulation with bacterial colonisation as identified by the presence of bacterial $16 \mathrm{~S}$ ribosomal RNA (rRNA) genes.

\section{METHODS}

\section{Patient groups}

Three groups of mechanically ventilated infants were studied: (1) preterm infants ( $<32$ weeks gestation) who developed mild, moderate or severe CLD using National Institute of Child Health criteria $^{1}$; (2) preterm infants who developed and recovered from neonatal respiratory distress syndrome (RDS); and (3) a control group comprising term infants who required ventilation for non-respiratory reasons needing $\leq 28 \%$ oxygen throughout the study period. Participants were recruited from the neonatal unit at the University Hospital of Wales, Cardiff between May 2005 and December 2006.

\section{Bronchoalveolar lavage}

BAL was performed as previously described. ${ }^{19} 20$ BAL fluid was collected daily for the first week of life then twice a week until 28 days of age or until extubation. Two aliquots of $1 \mathrm{ml} / \mathrm{kg}$ normal saline were instilled and suctioned immediately. Samples were centrifuged at $1000 \mathrm{~g}$ for $10 \mathrm{~min}$ at $4^{\circ} \mathrm{C}$ within 30 min of collection. The supernatant was aliquoted and stored at $-80^{\circ} \mathrm{C}$. Pelleted cells were resuspended in phosphate buffered saline, counted with a haemocytometer and cytospins were stained with 
Diff-Quik for cell differential counts. The unused cell suspension was recentrifuged and the pellet stored at $-80^{\circ} \mathrm{C}$.

\section{NE activity}

$\mathrm{NE}$ activity in BAL fluid was measured by the kinetic conversion of Suc-Ala-Ala-Pro-Val-pNA (Bachem, St Helens, UK), as described previously. ${ }^{11}{ }^{14}$ The specificity of free NE activity was verified by neutralisation with recombinant AAT (Arriva Pharmaceuticals, Alameda, California, USA).

\section{AAT analysis}

The protein concentration in BAL fluid was determined using a BCA Protein Assay Kit (Pierce, Rockford, Illinois, USA). BAL fluid AAT was analysed by western blot analysis with equal protein load as described elsewhere ${ }^{13}$ using horseradish peroxidase (HRP)-conjugated goat polyclonal anti-human AAT (AB7635; Abcam PLC, Cambridge, UK). Excess purified NE $(0.5 \mu \mathrm{g})$ was added to BAL fluid for $30 \mathrm{~min}$ at room temperature prior to western blot analysis when immunoreactive native AAT was observed coincident with NE activity to test specificity.

\section{SerpinB1 analysis}

SerpinB1 was assessed in equal volumes of BAL fluid by western blot analysis using a rabbit polyclonal anti-SerpinB1 primary and an HRP-conjugated goat anti-rabbit secondary antibody. ${ }^{21} \mathrm{~A}$ standard curve (3-30 ng) of recombinant SerpinB1 was included on each gel. SerpinB1 was quantified by densitometry using ImageJ software (http://rsb.info.nih.gov/ij/).

\section{Total MMP-9 and MMP-9/TIMP-1 complex}

These were measured by ELISA (R\&D Systems, Minneapolis, USA) according to the manufacturer's instructions.

\section{Bacterial 16S rRNA analysis}

Cell pellet DNA was isolated using the Qiagen RNA/DNA Mini kit (Qiagen, Crawley, UK). PCR was used to amplify the 16s rRNA gene using the primers 27f (5'-AGAGTTTGATC(AC) TGGCTCAG- $3^{\prime}$ ) and 1492r (5'-TACGG(CT)TACCTTGTTACGACTT-3'). ${ }^{22}{ }^{23}$ The integrity of extracted DNA was assessed by amplifying human mitochondrial cytochrome oxidase (HMCO) using specific primers. PCR products were separated on $0.7 \%$ agarose gels stained with ethidium bromide and visualised in a BioDoc-IT UV Transilluminator (Ultra-Violet Products, Cambridge, UK)

\section{Sequencing of 16s rRNA genes}

Amplicons from samples positive for 16s rRNA genes were purified using a Novagen spin-prep PCR clean-up kit (Merck Chemicals, Nottingham, UK) and sequenced using the BigDye Terminator V3.1 cycle sequencing kit (Applied Biosystems, Warrington, UK) and an ABI Prism 3130xl Genetic Analyzer (Applied Biosystems). Sources of bacterial $16 \mathrm{~S}$ rRNA genes were determined by amplicon sequence comparison using the BlastN website.

\section{Statistical methods}

Statistical analysis was performed using SPSS V.15.0. The Mann-Whitney U test was used for non-parametric data and correlations between groups were performed using Spearman correlation coefficients. The presence of NE or 16s rRNA genes between groups was compared using $\chi^{2}$ tests. $p$ Values of $<0.05$ were considered statistically significant.

\section{RESULTS \\ Patients}

Forty-two infants of $<32$ weeks' gestational age were recruited: 20 developed CLD (5 mild, 12 moderate, 3 severe CLD); 17 recovered from RDS; 5 infants died before they could be classified and were excluded from the analysis; there were also 6 term controls (table 1). Two hundred and twenty BAL fluid samples were collected: 130 from the CLD group, 45 from the RDS group, 22 from infants who died and 23 from term controls. The median BAL fluid yield was 50\% (IOR 38-63\%).

\section{Cell counts}

Median (IOR) peak cell counts in BAL fluid were statistically greater in infants developing CLD $\left(6.75 \times 10^{6}\right.$ cells $/ \mathrm{ml}$; $\left.3.54-17.9 \times 10^{6}\right)$ than in the RDS group $\left(2.22 \times 10^{6}\right.$ cells $/ \mathrm{ml}$; $\left.1.05-5.50 \times 10^{6}, \mathrm{p}=0.002\right)$ and controls $\left(0.63 \times 10^{6} \mathrm{cells} / \mathrm{ml}\right.$; $\left.0.156-1.26 \times 10^{6}, \mathrm{p}<0.001\right)$. The moderate/severe CLD group $\left(6.30 \times 10^{6} \mathrm{cell} / \mathrm{s} / \mathrm{ml} ; 3.97-11.3 \times 10^{6}\right)$ had a statistically greater peak cell count than the RDS group ( $p=0.005)$. Neutrophils dominated the cell counts but macrophages and some epithelial cells were observed. Peak neutrophil counts were statistically greater in infants developing CLD $\left(3.36 \times 10^{6}\right.$ cells $/ \mathrm{ml}$; $1.79-9.93 \times 10^{6}$ ) than in infants with resolved RDS $\left(1.14 \times 10^{6}\right.$ cells $\left./ \mathrm{ml} ; 0.65-2.88 \times 10^{6}, \mathrm{p}=0.005\right)$ and term controls $\left(0.38 \times 10^{6} \mathrm{cells} / \mathrm{ml} ; 0.048-0.63 \times 10^{6}, \mathrm{p}=0.001\right)$. Infants with moderate/severe CLD $\left(2.56 \times 10^{6} \mathrm{cells} / \mathrm{ml} ; 1.91-7.13 \times 10^{6}\right)$ had statistically more neutrophils than the RDS group.

\section{Elastase activity}

Free NE activity was detected in 26/198 BAL fluid samples $(13 \%)$. Statistically more infants who developed CLD (10/20) had free NE activity in at least one BAL fluid sample compared with the RDS group $(2 / 17, p=0.013)$ or controls $(0 / 6, p=0.027)$. Three of 5 infants with mild CLD had detectable NE in at least one BAL fluid sample. More infants with moderate/severe CLD had free NE detected in BAL fluid than infants in the RDS group $(p=0.035)$. No statistical difference was noted between the RDS and control groups. No sample from the term controls had free NE activity. NE activity was present in 23/129 (18\%) lavages from the infants developing CLD and in 3/46 (7\%) samples from infants with resolved RDS.

Detection of NE activity was episodic, with the day of first occurrence varying from days 2 to 26 (median 7 days), and NE activity coincided with increased BAL fluid cell counts (figure 1 and online data supplement). In all cases, NE activity was blocked by the addition of exogenous recombinant AAT (data not shown), suggesting an imbalance between proteinases and proteinase inhibitors.

Table 1 Patient characteristics

\begin{tabular}{llll}
\hline & $\begin{array}{l}\text { Chronic lung } \\
\text { disease }\end{array}$ & $\begin{array}{l}\text { Resolved } \\
\text { respiratory } \\
\text { distress } \\
\text { syndrome }\end{array}$ & Term control \\
\hline Number of patients & 20 & 17 & 6 \\
Number of samples & 130 & 45 & 23 \\
Gestational age (weeks) & 27 & $28+6$ & Term \\
Birth weight (g) & $\left(25^{+4}-29^{+3}\right)^{*}$ & $\left(27-29^{+2}\right)^{*}$ & \\
M:F & 835 & 1120 & 2550 \\
Vaginal:caesarean delivery & $(695-1025)$ & $(935-1315)$ & $(2090-2825)$ \\
Antenatal steroids & $11: 9$ & $10: 7$ & $3: 3$ \\
$>24 h$ & $10: 10$ & $6: 11$ & $5: 1$ \\
Surfactant therapy & $16 / 20(80 \%)$ & $12 / 17(71 \%)$ & $0 / 6(0 \%)$ \\
$\begin{array}{l}\text { Prolonged rupture of membranes } \\
\text { (>24 h) }\end{array}$ & $4 / 20(20 \%)$ & $1 / 17(6 \%)$ & $0 / 6$ \\
Length of ventilation (days) & $7(5.5-11)$ & $1(1-4.5)$ & 3 \\
\hline * Values are shown as median (IOR). & & \\
Superscript numbers indicate the number of days in addition to gestation in weeks.
\end{tabular}




\section{$\alpha_{1}$-Antitrypsin}

Western blotting detected free AAT as a $53 \mathrm{kDa}$ band, AATproteinase complex at $80 \mathrm{kDa}$ and apparent degraded AAT at $48 \mathrm{kDa}$ (figure 2A). AAT-NE complex was detected in 18/20 $(90 \%)$ infants who developed CLD, which is statistically more than $8 / 17(47 \%)$ infants whose RDS resolved $(p=0.004)$. The maximum percentage of complexed AAT as estimated by densitometry was statistically greater for infants in the CLD group (median 22\%; IOR 13-32\%) than for infants whose RDS resolved (median 0; $0-19 \%, \mathrm{p}=0.012$ ) and term controls (median $0 ; 0-9 \%, p=0.003)$, and between the RDS group and infants with moderate/severe CLD (median 22\%; 13.5-33.5\%, $\mathrm{p}=0.013$ ).

Interestingly, BAL fluid collected from some infants with CLD contained both free $\mathrm{NE}$ and unbound AAT (53 kDa) (figure 2B). In all cases when a molar excess of NE was incubated with the BAL fluid prior to western blot analysis, the unbound AAT $(53 \mathrm{kDa})$ formed a complex with $\mathrm{NE}$ or was degraded.

\section{SERPINB 1}

The median (IOR) SerpinB1 concentration on the first day of life was $155 \mathrm{ng} / \mathrm{ml}$ (64-414), which did not increase significantly over the first 5 days of life; no statistical difference was noted between the CLD and RDS groups over this period. Median (IOR) peak SerpinB1 concentrations were not statistically different between groups (CLD group: $400 \mathrm{ng} / \mathrm{ml}$; 185-2130; RDS group: $205 \mathrm{ng} / \mathrm{ml}$; 113-480, $\mathrm{p}=0.161)$ and term controls (163 ng/ml; 78-164, $\mathrm{p}=0.107)$. No statistical difference was seen between peak SerpinB1 concentrations in the RDS group and infants with moderate/severe CLD (455 ng/ml; 191.5-2130, $\mathrm{p}=0.157$ ). Episodic increases in SerpinB1 were observed more frequently in infants developing CLD than in a minority of RDS infants (figure 3), and these increased SerpinB1 episodes corresponded to episodic increases of cell counts, free NE and NE-AAT complexes (figure 1 and online supplement). Statistically more infants with CLD had covalently complexed SerpinB1 in at least one BAL fluid sample (11/20) compared with infants with resolved RDS (3/17), $p=0.020$. SerpinB1 complex was not observed in control infants.

\section{MMP-9}

Median (IOR) peak MMP-9 protein concentrations were statistically greater in infants who developed CLD (763 ng/ml; 200-1790) than in infants in the RDS group ( $47 \mathrm{ng} / \mathrm{ml} ; 20-352, \mathrm{p}=0.004$ ) and term controls $(74 \mathrm{ng} / \mathrm{ml} ; 36-250, \mathrm{p}=0.007)$. Infants with moderate/severe CLD (948 ng/ml; 252-2322) also had statistically greater MMP-9 than those with RDS $(\mathrm{p}=0.005)$. Peak MMP9/TIMP-1 complex concentrations were greater in infants who developed CLD $(29.9 \mathrm{ng} / \mathrm{ml} ; 13.1-51.3)$ than in the RDS group $(1.5 \mathrm{ng} / \mathrm{ml} ; 0.9-24.1, \mathrm{p}=0.004)$ and than infants with moderate/ severe CLD $(29.9 \mathrm{ng} / \mathrm{ml}$; 16.5-51.3) than in infants in the RDS group $(p=0.017)$. Differences between CLD and term infants $(7.0 \mathrm{ng} / \mathrm{ml} ; 1.4-24.2)$ were not statistically significant $(\mathrm{p}=0.068)$.

\section{Relationship between variables}

Strong correlations were observed between most peak values, particularly MMP-9 and MMP-9/TIMP-1 complexes and NE activity relative to the percentage of complexed SerpinB1 (table 2). In addition, there were strong temporal correlations between cell counts, proteinases and anti-proteinases (figure 1 and online supplement).

\section{Bacterial 16S rRNA genes}

DNA was extracted from 198 BAL fluid samples and satisfactory DNA integrity was confirmed in 162 by HMCO amplification by PCR (only three infants failed to have a satisfactory sample DNA). Bacterial 16S rRNA genes were detected in 75/162 (46\%) of these samples; statistically more infants who developed CLD had 16S rRNA genes in their BAL fluid at some point (14/19, $74 \%)$ than infants in the RDS group (5/16 (31\%), $\mathrm{p}=0.012)$ or term controls $(2 / 5(40 \%), p=0.155)$. Statistically more infants with moderate/severe CLD (11/14, 79\%) had 16s rRNA genes detected than infants in the RDS group $(p=0.001)$. Elastase activity was found in greater numbers of $16 \mathrm{~S}$ rRNA gene-positive
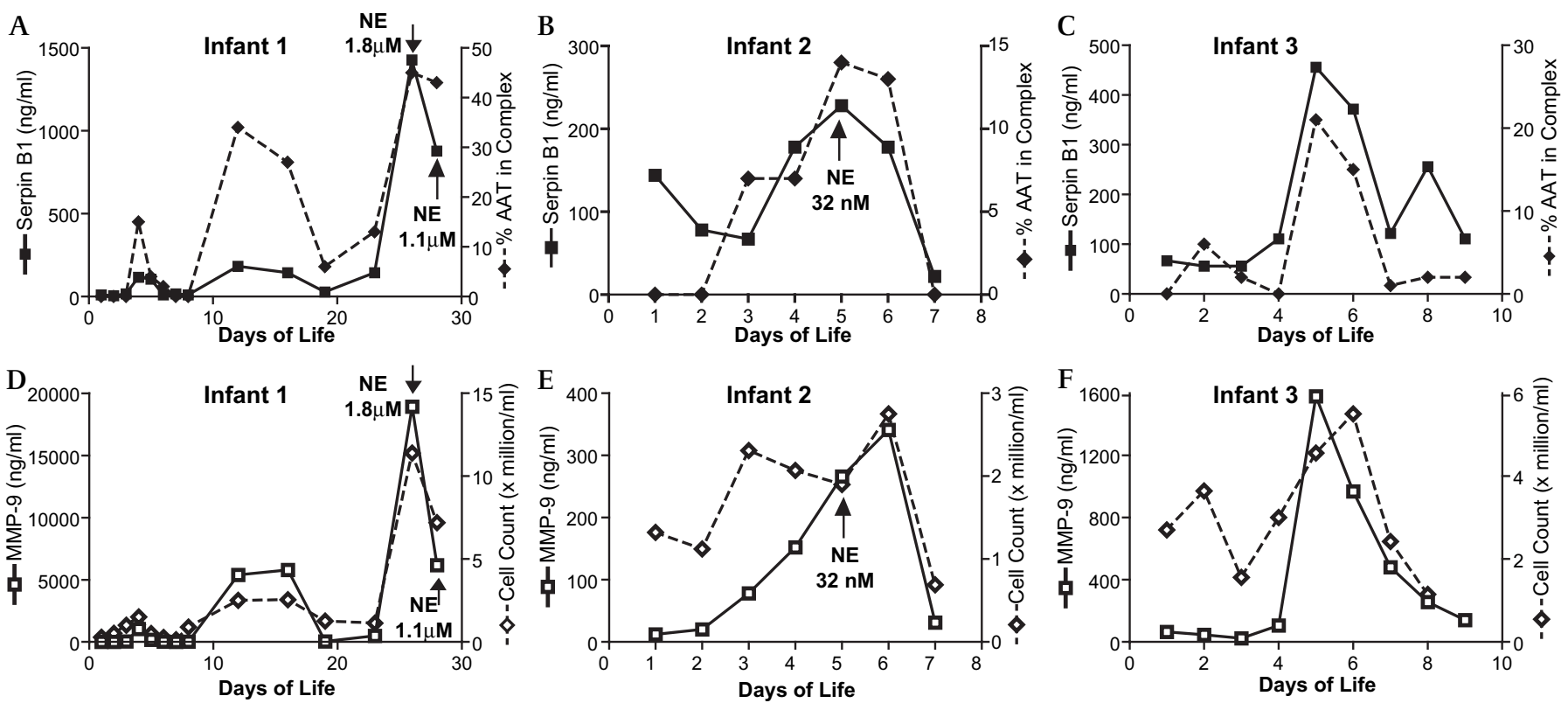

Figure 1 Longitudinal analysis of bronchoalveolar lavage fluid from three infants showing temporal relationships between variables. Graphs A-C show SerpinB1 concentrations (left axis, solid line) and the proportion of $\alpha_{1}$-antitrypsin (AAT) in complex with serine protease (right axis, broken line) relative to day of life (X-axis). Graphs D-F show the same infants with matrix metalloproteinase (MMP)-9 concentrations (left axis, solid line) and total cell counts (right axis, broken line) against days of life. The arrows indicate the days when free neutrophil elastase (NE) was detected. No free NE was detected in infant 3. 
A

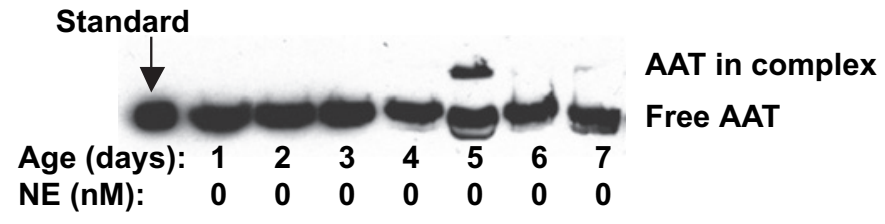

B

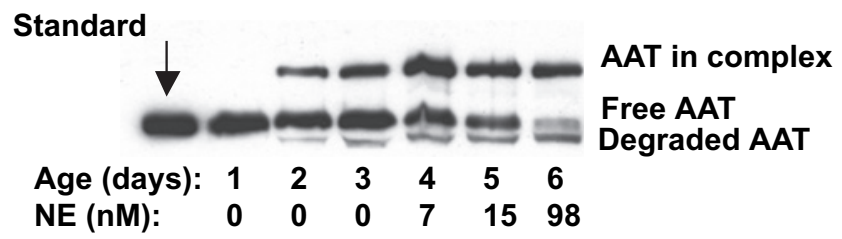

Figure 2 Western blot of $\alpha_{1}$-antitrypsin (AAT) species in sequential bronchoalveolar lavage $(B A L)$ fluid specimens for $(A)$ a representative infant from the resolved respiratory distress syndrome group in whom active neutrophil elastase (NE) was not detected and (B) an infant from the chronic lung disease of prematurity group in whom active NE was detected. Patient age and NE concentrations are shown below each lane of the western blot. Equal amounts of protein were loaded for analysis and the left lanes show purified plasma AAT migrating at $53 \mathrm{kDa}$ (standard). Additional bands in BAL fluid specimens are the complex with serine proteases at $80 \mathrm{kDa}$ and degraded $A A T$ at $48 \mathrm{kDa}$. Note that the day 1 samples for both infants contain free AAT only, while day 5 BAL fluid for patient $A$ and days 2-6 for patient $B$ also contain an additional higher AAT-proteinase complex. BAL fluid from days $2-6$ of patient $B$ also contains degraded AAT.

lavages $(19 / 75,25 \%)$ than $16 \mathrm{~S}$ rRNA gene-negative lavages $(5 / 87$ $(6 \%), p=0.009)$. Furthermore, elastase activity was higher in the $16 \mathrm{~S}$ rRNA gene-positive lavages than in the negative lavages (although the median value for both was zero, $\mathrm{p}=0.0018$ ). The median (IOR) total BAL fluid MMP-9 concentration was greater in $16 \mathrm{~S} \mathrm{rRNA}$ gene-positive lavages $(211 \mathrm{ng} / \mathrm{ml} ; 64-1047)$ than in $16 \mathrm{~S}$ rRNA gene-negative samples (44 ng/ml; 21-115, $\mathrm{p}<0.001)$.

PCR amplicon sequencing showed that the samples with the greatest NE activity and total MMP-9 concentrations contained virulent organisms such as Stegastes aureus and $E$ coli (figure 4A), while the RDS infants with free elastase and the highest MMP-9 concentrations had organisms regarded as being less virulent such as $S$ epidermidis (figure $4 \mathrm{~B}$ ).

\section{DISCUSSION}

This study provides a detailed profile of NE and its inhibitors, AAT (SerpinA1) and SerpinB1 as well as MMP-9 and MMP-9/

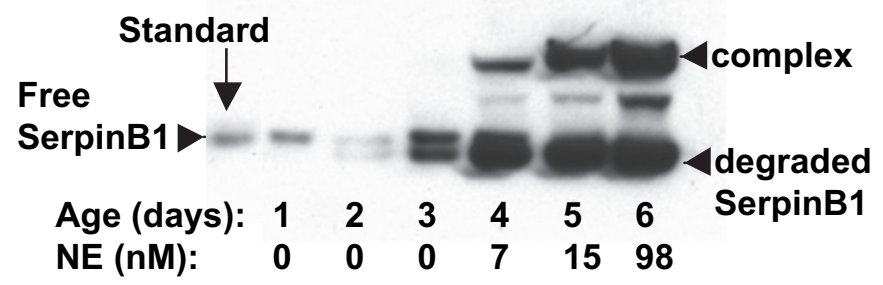

Figure 3 Western blot of SerpinB1 species in sequential bronchoalveolar lavage (BAL) fluid specimens of an infant with chronic lung disease of prematurity in whom active neutrophil elastase (NE) was detected. Equal volumes of BAL fluid were loaded for analysis and the left lane shows purified SerpinB1 (10 ng) migrating at $42 \mathrm{kDa}$ (standard). Other species present in BAL fluid are the $66 \mathrm{kDa}$ complex with serine proteinase, a partially degraded intermediate product and degraded SerpinB1 at $38 \mathrm{kDa}$. A statistically significant increase in both the total concentration and percentage in the complex is seen, occurring with increased NE activity.
Table 2 Correlation coefficients between maximum values of cell counts, neutrophil elastase (NE) activity, matrix metalloproteinase (MMP)-9 concentrations, SerpinB1 concentrations, percentage $\alpha_{1}$-antitrypsin (AAT) and SerpinB1 in complex and MMP-9/TIMP-1 concentrations in BAL fluid from ventilated newborn infants

\begin{tabular}{|c|c|c|}
\hline Maximum value & Maximum value & $\begin{array}{l}\text { Spearman's } \\
\text { correlation } \\
\text { coefficient } \\
\text { (p value) }\end{array}$ \\
\hline $\log _{10}$ MMP-9 & $\log _{10}$ MMP-9/TIMP-1 & 0.94 \\
\hline $\log _{10}$ elastase & \% SerpinB1 in complex & 0.88 \\
\hline $\log _{10}$ SerpinB1 & \% SerpinB1 in complex & 0.76 \\
\hline $\log _{10}$ MMP-9 & $\log _{10}$ cell count & 0.75 \\
\hline $\log _{10}$ elastase & $\log _{10}$ neutrophil count & 0.71 \\
\hline $\log _{10}$ neutrophil count & \% SerpinB1 in complex & 0.70 \\
\hline $\log _{10}$ elastase & $\log _{10}$ SerpinB1 & 0.68 \\
\hline $\log _{10}$ elastase & $\log _{10}$ cell count & 0.65 \\
\hline $\log _{10}$ elastase & $\log _{10}$ MMP-9 & 0.65 \\
\hline$\%$ AAT in complex & \% SerpinB1 in complex & 0.64 \\
\hline$\%$ AAT in complex & $\log _{10}$ elastase & 0.62 \\
\hline $\log _{10}$ neutrophil count & $\log _{10}$ SerpinB1 & 0.62 \\
\hline $\log _{10}$ cell count & $\log _{10}$ SerpinB1 & 0.59 \\
\hline
\end{tabular}

Statistical analysis for all correlations shown were statistically significant at $p<0.001$.

TIMP-1 complex in ventilated preterm infants. It identified relationships between proteolytic enzymes and their inhibitors and highlights the importance of postnatal infection in proteinase release and in the development of CLD.

Our study is the most detailed longitudinal analysis to date of NE activity in CLD and includes the previously unstudied SerpinB1. Previous studies examined NE at single time points ${ }^{11} 1314$ or examined a limited number of samples. ${ }^{12}{ }^{15}$ We found that NE activity was episodic and frequently occurred relatively late in the development of CLD, which may cause NE activity to be missed when summary data are presented rather than longitudinally for individual infants. BAL fluid studies of intubated infants prevent comparisons with patients with RDS at equivalent time points. However, our data suggesting that infection may lead to dysregulated inflammation are in agreement with published evidence that prolonged mechanical ventilation commonly results in the development of pneumonia. ${ }^{24}$

Some infants developed CLD without NE activity being detected. It is possible that NE activity occurred between lavages or following extubation. Also, NE activity may be increased in the pericellular environment as suggested by the presence of complexed AAT and SerpinB1. These complexes, which may be regarded as surrogate markers for regulated NE release, were present in far more samples than was free NE, particularly in infants developing CLD, suggesting successful regulation of proteinases. The simultaneous presence of free $\mathrm{NE}$ and unbound AAT $(53 \mathrm{kDa})$ was interesting. This may reflect oxidation of the AAT reactive site methionine residue resulting in a decreased rate of NE-AAT complex formation. ${ }^{25}$ Thus complex formation occurred after in vitro incubation for a further $30 \mathrm{~min}$ with excess NE. Alternatively, increased proteinases including MMP-9 may degrade and inactivate AAT leading to more NE activity. Infection may trigger this dysregulation as it was closely correlated with the increased NE.

SerpinB1 has not been studied in human newborn infants but has been examined in a baboon CLD model. ${ }^{26}$ Higher NE activity was reported in baboons with "classical" compared with "new" CLD. Baboons developing "new" CLD had 2.5 times the level of SerpinB1 mRNA in BAL fluid compared with term controls, while "classical" CLD was associated with lower SerpinB1 
Figure 4 Scatterplots of (A) peak elastase activity and (B) matrix metalloproteinase (MMP)-9 concentrations for each diagnostic class of infant. Filled symbols indicate $16 \mathrm{~S}$ rRNA gene-positive specimens and empty boxes indicate negative specimens. Sequencing data for $16 \mathrm{~S}$ rRNA gene-positive organisms are also shown. Some samples were identified as $16 \mathrm{~S}$ rRNA gene-positive but no specific microorganism was identified by sequencing. Abbreviations for microorganisms include $S$ epi (S epidermidis), $S$ haem (S haemolyticus) and $P$ aeru ( $P$ aeruginosa). CLD, chronic lung disease of prematurity; RDS, respiratory distress syndrome.
A
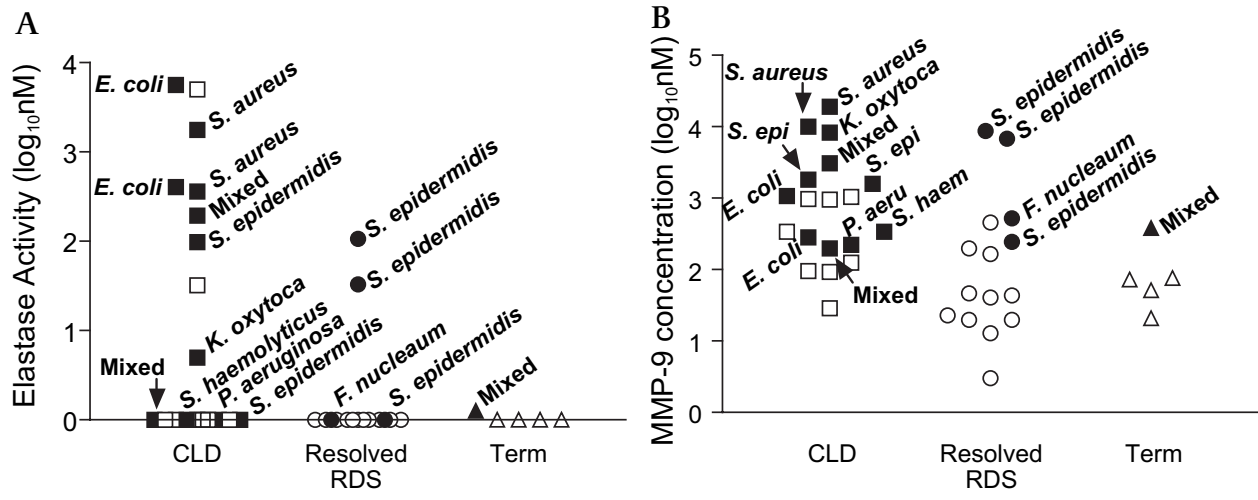

concentrations. We thus hypothesised that a higher SerpinB1 content in "new" CLD may reduce NE activity in human patients and we did find a trend towards higher SerpinB1 levels in infants with CLD than in those with RDS and controls. Temporal relationships were noted between SerpinB1 concentration, active NE and the percentage of SerpinB1 complexed with proteinase, which suggests that the SerpinB1 increase was part of a protective mechanism to regulate NE activity.

AAT is an acute phase reactant. ${ }^{27}$ Merritt et al $l^{8}$ showed that the AAT concentration almost doubled in lung lavages from infants developing classical CLD. However, we have shown that the SerpinB1 concentration increased locally and rapidly in association with increased NE activity. Moreover, the increase in SerpinB1 was far greater $(>10$-fold increase for some neonates, figure 3) than has previously been described for $\mathrm{AAT}^{8}$ and may be more important in neutralising NE activity. The mechanisms of SerpinB1 release are unknown as the protein lacks an $\mathrm{N}$-terminal classical secretion sequence. ${ }^{28}$ The BAL fluid concentration of SerpinB1 correlated well with infiltrating inflammatory cells, particularly neutrophils (which contain the highest concentration of SerpinB1); therefore, SerpinB1 may have been released following cell death or by a non-classical mechanism. However, the possibility of SerpinB1 upregulation and release cannot be discounted. ${ }^{29}$ Our finding of SerpinB1 increasing in parallel with inflammation is in keeping with those reported in patients with cystic fibrosis where a similar correlation between SerpinB1 levels and neutrophil numbers was also noted. ${ }^{30}$

The simultaneous episodic increases of neutrophils, proteinases (NE and MMP-9) and anti-proteinases (AAT and SerpinB1) indicate a triggered inflammatory process leading to an increased likelihood of developing CLD; postnatal infection was the most likely candidate to trigger the inflammation. The role of postnatal infection in the development of CLD is recognised ${ }^{31}{ }^{32}$ but is frequently underrated. Conventional culture techniques of BAL fluid are confounded by frequent administration of broad-spectrum antibiotics in these patients. Microbial infection or colonisation has previously been confirmed by identification of $16 \mathrm{~S}$ rRNA genes. ${ }^{33-35}$ Our finding of $16 \mathrm{~S}$ rRNA genes detection in patients developing CLD lends further support to postnatal infection being integral in the pathogenesis of CLD. NE was detected more frequently and in higher levels for BAL fluid samples when 16S rRNA genes were detected. This suggests that infection rather than microbial colonisation of the airways is responsible for episodic spikes of protective proteinases and inhibitors.

Previous studies of MMP-9 have reported conflicting results. Dik et $a l^{17}$ showed an increased MMP-9 concentration on days 2 and 4 of life in infants with RDS compared with those with CLD, but Sweet et $a l^{5}$ and Ekekezie et $a l^{6}$ found no statistical difference in MMP-9 levels between groups although both reported a higher ratio of MMP-9 to TIMP-1 in the BAL fluid of infants with CLD. Danan et $a l^{7}$ showed that MMP-9 concentrations, primarily of inactive pro-MMP-9, were increased early in life, but no difference was noted between infants with CLD and those with RDS. Studies of baboons found higher MMP-9 concentrations in extremely premature animals with CLD. ${ }^{16}$ Our longitudinal study of human infants suggests that MMP-9 may be important in the development of CLD and, as with NE, the increased concentrations were episodic. MMP-9/TIMP-1 concentrations in neonatal BAL fluid have not been reported previously. We found a strong correlation between total MMP-9 and MMP-9/TIMP-1 complex concentrations; however, only a small proportion of total MMP-9 appeared to be in complex with TIMP-1. Furthermore, western blot analysis of our BAL fluid (data not shown) showed that more than half of the MMP-9 was present as dimer rather than monomer, which may interfere with TIMP-1 binding, and the mass of the monomer MMP-9 appeared to be mostly present as the pro-enzyme form. Our finding of an increased MMP-9 concentration in 16S rRNA gene-positive samples suggests that the episodic spikes observed in proteinase concentrations is probably due to infective episodes.

The sequencing data suggest that, while a number of organisms may be associated with high peaks of elastase and MMP-9, those infants who develop CLD had more virulent organisms within their BAL fluid. $S$ aureus and $E$ coli were particularly prominent in infants with CLD with BAL fluid elastase present, while the higher proteinase activity in the BAL fluid of infants whose RDS resolved was associated with $S$ epidermidis, which is frequently dismissed as a commensal.

In conclusion, our study gives a detailed longitudinal profile of NE and MMP-9 and their inhibitors AAT and SerpinB1 as well as MMP-9/TIMP-1 concentrations in the lungs of preterm infants. It showed that episodic peaks of both proteinases and their inhibitors occurred, which may be important in the development of CLD, and we suggest that postnatal infection is a crucial trigger for inflammatory infiltration and proteinase release leading to lung injury resulting in CLD development.

Acknowledgements We are grateful for the assistance of Jessica Cooley (Immune Disease Institute, Boston, Massachusetts, USA) and colleagues from the neonatal unit in Cardiff, UK. In particular, we would like to thank the parents and infants who participated in this study. 
Contributors PLD and OBS contributed equally to the research and preparation of the manuscript and share first co-authorship. All authors listed contributed significantly to the research that resulted in the submitted manuscript.

Funding Arriva Pharmaceuticals Inc, 1010 Atlantic Avenue, Alameda, CA 94501, USA. Other funders: NIH (HL066548) to ERO and Wellcome Trust.

Competing interests None.

Ethics approval This study was conducted with the approval of the South Wales local research ethics committee and written informed consent was obtained from the parents of study subjects.

Provenance and peer review Not commissioned; externally peer reviewed.

\section{REFERENCES}

1. Jobe AH, Bancalari E. Bronchopulmonary dysplasia. Am J Respir Crit Care Med 2001:163:1723-9

2. Northway WH Jr, Rosan RC, Porter DY. Pulmonary disease following respirator therapy of hyaline-membrane disease. Bronchopulmonary dysplasia. N Engl J Med 1967;276:357-68.

3. Coalson JJ. Pathology of new bronchopulmonary dysplasia. Semin Neonatol 2003;8:73-81

4. Lee WL, Downey GP. Leukocyte elastase: physiological functions and role in acute lung injury. Am J Respir Crit Care Med 2001;164:896-904.

5. Sweet DG, Curley AE, Chesshyre $E$, et al. The role of matrix metalloproteinases -9 and -2 in development of neonatal chronic lung disease. Acta Paediatr 2004;93:791-6.

6. Ekekezie II, Thibeault DW, Simon SD, et al. Low levels of tissue inhibitors of metalloproteinases with a high matrix metalloproteinase-9/tissue inhibitor of metalloproteinase-1 ratio are present in tracheal aspirate fluids of infants who develop chronic lung disease. Pediatrics 2004:113:1709-14.

7. Danan C, Jarreau PH, Franco ML, et al. Gelatinase activities in the airways of premature infants and development of bronchopulmonary dysplasia. Am J Physiol Lung Cell Mol Physiol 2002:283:L1086-93.

8. Merritt TA, Cochrane CG, Holcomb K, et al. Elastase and alpha 1-proteinase inhibitor activity in tracheal aspirates during respiratory distress syndrome. Role of inflammation in the pathogenesis of bronchopulmonary dysplasia. J Clin Invest 1983;72:656-66.

9. Ogden BE, Murphy SA, Saunders GC, et al. Neonatal lung neutrophils and elastase/ proteinase inhibitor imbalance. Am Rev Respir Dis 1984;130:817-21.

10. Watterberg KL, Carmichael DF, Gerdes JS, et al. Secretory leukocyte protease inhibitor and lung inflammation in developing bronchopulmonary dysplasia. J Pediatr 1994;125:264-9.

11. Speer CP, Ruess D, Harms K, et al. Neutrophil elastase and acute pulmonary damage in neonates with severe respiratory distress syndrome. Pediatrics 1993:91:794-9.

12. Groneck $\mathbf{P}$, Gotze-Speer B, Oppermann M, et al. Association of pulmonary inflammation and increased microvascular permeability during the development of bronchopulmonary dysplasia: a sequential analysis of inflammatory mediators in respiratory fluids of high-risk preterm neonates. Pediatrics 1994;93:712-8.

13. Griese M. Pudenz P. Gebhard W. Inhibitors of elastase in airway lavage samples from ventilated preterm human neonates. Am J Respir Crit Care Med 1998;158:256-62.

14. Sluis KB, Darlow BA, Vissers MC, et al. Proteinase-antiproteinase balance in tracheal aspirates from neonates. Eur Respir J 1994:7:251-9.

15. Sveger T, Ohlsson K, Polberger S, et al. Tracheobronchial aspirate fluid neutrophil lipocalin, elastase- and neutrophil protease-4-alpha1-antitrypsin complexes, protease inhibitors and free proteolytic activity in respiratory distress syndrome. Acta Paediatr 2002;91:934-7.
16. Tambunting F, Beharry KD, Hartleroad J, et al. Increased lung matrix metalloproteinase-9 levels in extremely premature baboons with bronchopulmonary dysplasia. Pediatr Pulmonol 2005;39:5-14.

17. Dik WA, van Kaam AH, Dekker T, et al. Early increased levels of matrix metalloproteinase- 9 in neonates recovering from respiratory distress syndrome. Biol Neonate 2006:89:6-14.

18. Cederqvist K, Sorsa T, Tervahartiala T, et al. Matrix metalloproteinases-2, -8 , and -9 and TIMP-2 in tracheal aspirates from preterm infants with respiratory distress. Pediatrics 2001:108:686-92.

19. Kotecha S, Wilson L, Wangoo A, et al. Increase in interleukin (IL)-1 beta and IL-6 in bronchoalveolar lavage fluid obtained from infants with chronic lung disease of prematurity. Pediatr Res 1996:40:250-6.

20. de Blic J, Midulla F, Barbato A, et al. Bronchoalveolar lavage in children. ERS Task Force on bronchoalveolar lavage in children. European Respiratory Society. Eur Respir $J$ 2000;15:217-31.

21. Rees DD, Rogers RA, Cooley J, et al. Recombinant human monocyte/neutrophil elastase inhibitor protects rat lungs against injury from cystic fibrosis airway secretions. Am J Respir Cell Mol Biol 1999;20:69-78.

22. Davies CE, Hill KE, Wilson MJ, et al. Use of $16 \mathrm{~S}$ ribosomal DNA PCR and denaturing gradient gel electrophoresis for analysis of the microfloras of healing and nonhealing chronic venous leg ulcers. J Clin Microbiol 2004;42:3549-57.

23. Lane DJ. 16S/23S rRNA sequencing. In: Stackebrandt E, Goodfellow M, eds. Nucleic acid techniques. Bacterial systematics. London: Wiley, 1991:115-75.

24. Apisarnthanarak A, Holzmann-Pazgal G, Hamvas A, et al. Ventilator-associated pneumonia in extremely preterm neonates in a neonatal intensive care unit: characteristics, risk factors, and outcomes. Pediatrics 2003;112:1283-9.

25. Padrines M, Scneider-Pozzer M, Bieth JG. Inhibition of neutrophil elastase by alpha1-proteinase inhibitor oxidized by activated neutrophils. Am Rev Respir Dis 1989;139:783-90.

26. Yasumatsu R, Altiok 0, Benarafa C, et al. SERPINB1 upregulation is associated with in vivo complex formation with neutrophil elastase and cathepsin $\mathrm{G}$ in a baboon model of bronchopulmonary dysplasia. Am J Physiol Lung Cell Mol Physiol 2006;291:L619-27.

27. Ito H, Kishikawa T, Yamakawa Y, et al. Serum acute phase reactants in pediatric patients; especially in neonates. Jpn J Surg 1983;13:506-11.

28. Remold-0'Donnell E, Chin J, Alberts M. Sequence and molecular characterization of human monocyte/neutrophil elastase inhibitor. Proc Natl Acad Sci U S A 1992:89:5635-9.

29. Zeng W, Remold-O'Donnell E. Human monocyte/neutrophil elastase inhibitor (MNEI) is regulated by PU.1/Spi-1, Sp1, and NF-kappaB. J Cell Biochem 2000;78:519-32.

30. Cooley JRF, Sontag MK, Osberg I, et al. MNEl (monocyte/neutrophil elastase inhibitor) is found at increased levels in cystic fibrosis lavage fluid. Pediatr Pulmonol 2001;32(Suppl 22):271.

31. Groneck P, Goetze-Speer B, Speer CP. Inflammatory bronchopulmonary response of preterm infants with microbial colonisation of the airways at birth. Arch Dis Child Fetal Neonatal Ed 1996; 74:F51-5.

32. Walti H, Tordet C, Gerbaut L, et al. Persistent elastase/proteinase inhibitor imbalance during prolonged ventilation of infants with bronchopulmonary dysplasia: evidence for the role of nosocomial infections. Pediatr Res 1989;26:351-5.

33. Kotecha S, Hodge R, Miralles R, et al. Presence of pulmonary Ureaplasma urealyticum is associated with acute pulmonary inflammation in preterm infants. Pediatr Res 2004;55:61-8.

34. Oyarzún $\mathbf{E}$, Yamamoto $\mathrm{M}$, Kato $\mathrm{S}$, et al. Specific detection of 16 micro-organisms in amniotic fluid by polymerase chain reaction and its correlation with preterm delivery occurrence. Am J Obstet Gynecol 1998;179:1115-9.

35. Miralles R, Hodge R, McParland PC, et al. Relationship between antenatal inflammation and antenatal infection identified by detection of microbial genes by polymerase chain reaction. Pediatr Res 2005;57:570-7. 